\begin{tabular}{|c|c|c|}
\hline $\begin{array}{l}\text { PKS } \\
\text { PUBLIC } \\
\text { KNDOLEDGE } \\
\text { PROJECT }\end{array}$ & $\begin{array}{c}\text { REVISTA DE GEOGRAFIA } \\
\text { (RECIFE) } \\
\text { http://www.revista.ufpe.br/revistageografia }\end{array}$ & $\begin{array}{l}\text { OJS } \\
\text { OPEN } \\
\text { JOUNAL } \\
\text { SYSTEMS }\end{array}$ \\
\hline
\end{tabular}

\title{
O CAPITAL MINERADOR E A NOVA DINÂMICA ECONÔMICA E TERRITORIAL DO MUNICÍPO DE ALTO HORIZONTE - GOIÁS
}

\author{
Hamilton Matos Cardoso Júnior ${ }^{1}$; Flavia Maria de Assis Paula ${ }^{2}$ : Divina Aparecida Leonel \\ Lunas $^{3}$
}

${ }^{1}$ Mestre em Ciências Sociais e Humanidades pelo Programa de Mestrado em Território e Expressões Culturais no Cerrado pela Universidade Estadual de Goiás. E-mail: hjuniorgo@hotmail.com

${ }_{2}^{2}$ Professora efetiva do curso de Licenciatura em Geografia na Universidade Estadual de Goiás. Email: flaviama@hotmail.com

${ }^{3}$ Professora efetiva da Universidade Estadual de Goiás. Email: divalunas@gmail.com

Artigo recebido em 30/04/2017 e aceito em 12/12/2017.

\begin{abstract}
RESUMO
O município de Alto Horizonte firma-se como um dos principais polos de extração mineral em Goiás, bem como do Brasil, sendo o que mais contribuiu para o valor de extração mineral goiana nos últimos anos. Este artigo tem como objetivo realizar uma análise sobre a presença do capital minerador no município de Alto Horizonte, indicando e analisando as mudanças socioespaciais e econômicas que esse capital tem provocado. Para tanto, procedeu-se utilizando alguns passos metodológicos: pesquisa bibliográfica, pesquisa de campo, aplicação de questionários/entrevistas, produção de mapas e análise e tabulação de dados. Por meio desta pesquisa, percebe-se que o município de Alto Horizonte possui realidade econômica distinta dos demais da região norte de Goiás, sendo a presença do capital minerador fator determinante para a nova dinâmica econômica e territorial que o município tem apresentado.
\end{abstract}

Palavras-chave: Crescimento Econômico. Minérios. Território.

\section{THE MINER CAPITAL AND THE NEW ECONOMIC AND TERRITORIAL DYNAMICS IN THE MUNICIPALITY ALTO HORIZONTE - GOIÁS}

\begin{abstract}
The municipality of Alto Horizonte steady as one of the main poles of mineral extraction in Goiás, Brazil, being that most contributed to the value of mineral extraction goiano in recent years. This article aims to carry out an analysis of the presence of mining in the municipality capital of Alto Horizonte, showing and analyzing socioespaciais and economic changes that capital has caused. To do so, using some methodological steps: bibliographical research, field research, applying questionnaires/interviews and production of maps with the analysis and data tab. Through this research, the municipality of Alto Horizonte has distinct economic realities of the region North of Goiás, and the presence of mining capital determining factor for new economic and territorial dynamics that the municipality has presented.

Keywords: Economic growth. Ores. Territory.
\end{abstract}




\section{INTRODUÇÃO}

Segundo Castro (2006), a exploração mineral foi fator decisivo no povoamento do estado de Goiás e fator determinante em sua formação territorial. Durante o século XVIII foi sua principal atividade econômica, cedendo espaço à pecuária de subsistência no século XIX em virtude de seu declínio no fim daquele século (ESTEVAM, 2004).

Os rumores de novas áreas com potencial mineral em Goiás ressurgem apenas no início dos anos de 1900 com a descoberta da jazida de níquel no norte do estado. De acordo com dados levantados por Castro (2006), na década de 1950, Goiás participava com apenas $0,5 \%$ da produção mineral do país. Com a descoberta de novas jazidas durante o século XX e sua posterior exploração, o estado passa a ocupar o sexto lugar entre os maiores extratores de minérios do Brasil na década de 1980 (SCHAMALTZ, 1983), vindo a ocupar em 1997 a quarta posição, atrás apenas dos estados de Minas Gerais, Pará e São Paulo.

Atualmente, a exploração mineral goiana é alicerçada em conhecimentos científicos, técnicos e mercadológicos. A estrutura produtiva é sólida, lucrativa e está apoiada no modo de produção industrial. O setor tem desempenhado cada vez mais papel de importância na economia do estado.

Nesse contexto, tem ganhado destaque o município de Alto Horizonte, que desde o ano de 2006 vem sendo apropriado pelo capital minerador devido as suas riquezas minerais recentemente conhecidas. Este artigo tem como intuito discorrer sobre as principais consequências da presença do capital minerador no município de Alto Horizonte a partir do ano de 2004. O recorte temporal definido para esta pesquisa foi do ano de 2004 a 2014, dez anos da instalação da mineração nesse município. Para o alcance do objetivo proposto elegeram-se os seguintes passos metodológicos: pesquisa bibliográfica, pesquisa de campo, aplicação de questionários/entrevistas, produção de mapas e análise e tabulação de dados.

Este trabalho divide-se em cinco seções. Nesse sentido, a primeira seção realiza uma breve exposição da evolução histórica do município de Alto Horizonte destacando sua importância para o setor mineral. A segunda seção indica os agentes econômicos, os recursos extraídos e os mercados consumidores dessa produção. Já a terceira seção realiza uma discussão sobre a nova dinâmica econômica do município devido à presença do setor mineral. A quarta seção apresenta as influências do capital minerador na dinâmica territorial do município. E, por fim, na quinta e última seção, apresentam-se as considerações finais a respeito da temática. 


\section{ALTO HORIZONTE: BREVE HISTÓRICO}

O município de Alto Horizonte (Figura 1) é um dos 246 municípios do estado de Goiás. De acordo com dados do Instituto Brasileiro de Geografia e Estatística (IBGE, 2016), no ano de 2010 a população desse município era de 4.505 habitantes (IBGE, 2016) e seu PIB (Produto Interno Bruto), no ano de 2014, atingiu a marca dos R 471 milhões (IBGE, 2016), o quer o colocava na liderança dos municípios goianos ao se tratar do PIB per capita, chegando a $\mathrm{R} \$ 88$ mil por habitante.

Figura 1: Mapa de localização do município de Alto Horizonte em Goiás, 2016.

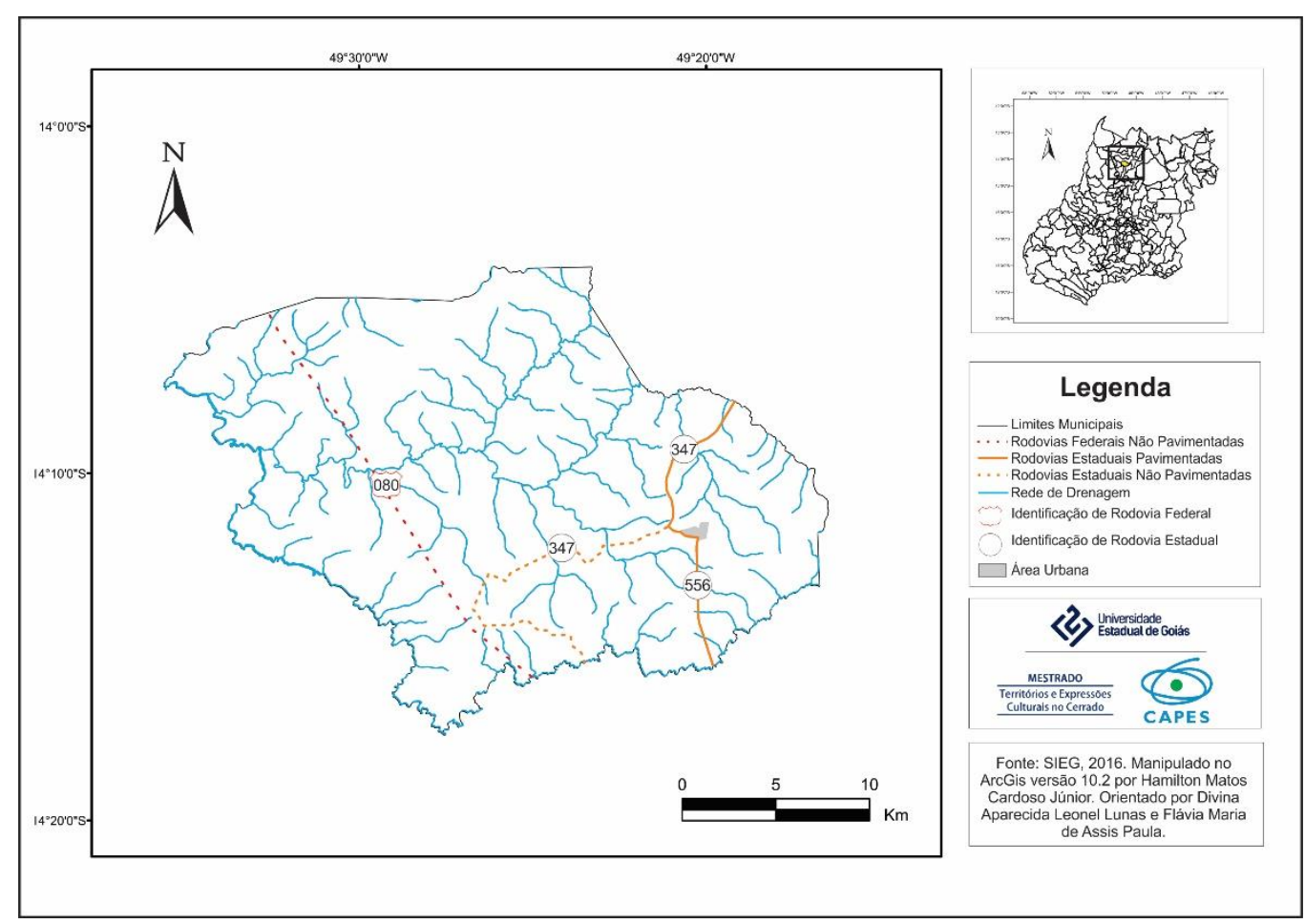

O município possui 23 anos de emancipação. No entanto, sua história de ocupação remonta ao ano de 1949. Localiza-se a 311 km de Goiânia e a 317 km de Brasília. O principal acesso ao município se dá pela BR-153 (partindo de Goiânia) e pela BR-080 (partindo de Brasília). Alto Horizonte pertence à mesorregião do norte goiano e à microrregião de Porangatu.

De acordo com o histórico das cidades do Instituto Brasileiro de Geografia e Estatística (IBGE, 2014), inicialmente o município de Alto Horizonte pertencia ao território do Mara Rosa, obtendo sua emancipação no ano de 1991 por meio da Lei n 11.399 de 16 de 
janeiro de 1991. Sua economia sempre esteve atrelada à agricultura e pecuária leiteira (IBGE, 2014).

A realidade econômica e social desse município só passa a apresentar um novo contexto a partir de 2004, momento da chegada da grande indústria mineral. Descobrem-se em seu solo ricos depósitos de minérios. Dentre eles, estão principalmente as substâncias metálicas (ouro e cobre), além de pequenas reservas de rochas de revestimento.

No decorrer do período de 2004 a 2014 foram investidos cerca de R\$ 34 milhões em pesquisa mineral, essenciais para a descoberta de grandes reservas na mina intitulada Chapada (DNPM, 2015).

A reserva de ouro foi medida no ano de 2014 em 52,586 milhões de toneladas (DNPM, 2015), sendo a maior reserva dessa substância no estado, concentrando 65,53\% das reservas goianas. Já a reserva de cobre foi medida no mesmo ano em 703,399 mil toneladas (DNPM, 2015), sendo a segunda maior reserva do estado, concentrando 17,14\% das reservas.

A extração mineral em Alto Horizonte caracteriza-se pela intensa presença do capital industrial, pela automação e mecanização do processo produtivo ${ }^{1}$. Esse aspecto é corroborado pelos dados obtidos no Departamento Nacional de Produção Mineral (DNPM, 2015), os quais demonstram que no período de 2004 a 2014 foram investidos mais de R\$ 1.9 bilhão na Mina da Chapada.

Como resultado da exploração de ser recursos, atualmente, ano de 2014, o município de Alto Horizonte assume a liderança como maior extrator de minérios do estado de Goiás, possuindo a maior contribuição no valor de produção estadual, que representava $21,28 \%$ desse valor (DNPM/GO, 2015). Devido a essa economia, Alto Horizonte exportou mais de 470 milhões de dólares no ano de 2014, sendo o segundo do ranking nesse ano em Goiás, atrás de Rio Verde e à frente de Luziânia (SEGPLAN, 2015).

\section{A EXPLORAÇÃO MINERAL EM ALTO HORIZONTE}

Cabe destacar que, atualmente, o setor mineral tem sido a força hegemônica preponderante na economia do município de Alto Horizonte. Segundo o Instituto Brasileiro de Geografia e Estatística (IBGE, 2017), o setor industrial, com bases na extração mineral, participou com $67 \%$ do valor adicionado a preços brutos básicos do município no ano de 2014.

\footnotetext{
1 Esse capital é de origem privada e internacional, sendo resultado dos investimentos de uma empresa considerada transnacional, como é destacado Na seção a seguir.
} 
Durante este estudo, por meio da pesquisa documental e do trabalho de campo, procurou-se identificar quais eram os principais agentes do crescimento econômico ${ }^{2}$ em Alto Horizonte. Pôde-se constatar que o principal agente responsável é o grupo Yamana Gold.

A Yamana Gold é uma transnacional com sede no Canadá, extratora de ouro, cobre e outras substâncias. Essa empresa possui significativa parcela da exploração de ouro no Brasil, além de possuir outras áreas em pesquisa e direitos em outros países da América Latina como: Chile, Argentina, México e Colômbia (IBRAM, 2014). Segundo o Instituto Brasileiro de Mineração (IBRAM, 2012):

O plano da Yamana é continuar a crescer a partir desta base, por meio da expansão e aumento da produção das minas em funcionamento, do desenvolvimento de novas minas, de avanços nas áreas em pesquisa e permanecendo atenta a outras oportunidades de consolidação de operações com ouro, com foco primário nas Américas. (IBRAM, 2012)

A Yamana Gold, por meio da Maracá Indústria e Comércio S.A, sua subsidiária, é o principal agente das transformações na dinâmica econômica e territorial no município de Alto Horizonte. Ela participou com 2,60\% do Valor de Produção Comercializada (VPC) no país em 2009 (DNPM, 2010), sendo o município de Alto Horizonte determinante para essa colocação.

No município ainda existem outros agentes que auxiliam em seu crescimento econômico, mas todos são prestadores de serviço à Maracá Indústria e Comércio S.A. Assim, esses agentes estão ligados à atividade de extração mineral. Dentre eles podem-se listar empresas de sondagem mineral; de transportes para os trabalhadores; de aluguel de maquinário para o campo de extração; de abastecimento de alimentos e refeições para os trabalhadores; além de empresa que terceirizam ${ }^{3}$ funcionários para o campo de extração.

Em relação às substâncias minerais extraídas no município, contatou-se que estas são o cobre e o ouro, com destaque para o primeiro. Segundo o Ministério de Minas e Energia (MME, 2009), as minas de cobre distribuíam-se por nove estados brasileiros no ano de 2005. Dentre estes, o destaque era o Pará, que abrigava $85,3 \%$ das reservas dessa substância, seguido por Goiás $(5,7 \%)$, Bahia (4,2\%), Alagoas $(2,2 \%)$ e Ceará $(1,9 \%)$.

\footnotetext{
${ }^{2}$ No dicionário de economia, crescimento econômico significa o aumento da capacidade produtiva da economia e, portanto, da produção de bens e serviços de terminado país ou área econômica. $\mathrm{O}$ crescimento é calculado mediante a evolução de crescimento anual do Produto Nacional Bruto - PND, ou pelo Produto Interno Bruto PIB. O crescimento de uma economia é indicado ainda como a mensuração do crescimento da sua força de trabalho, a receita nacional poupada e investida e o grau de aperfeiçoamento tecnológico. (VIEIRA; SANTOS, 2012, p. 347).

${ }^{3}$ Segundo a Costa (2014), a empresa Maracá possui, em 2014, 810 empregados terceirizados, o que corresponde a $61 \%$ de seu quadro.
} 
Com relação à extração dessa substância no país: “A mineração de cobre brasileira [...] é realizada predominantemente nos estados do Pará e Goiás, que juntos correspondem por cerca de $85 \%$ da produção do país, sendo que o primeiro Estado provém cerca de $57 \%$ do total" (MME, 2009, p. 12).

Já o ouro possui ampla distribuição geográfica, com suas maiores reservas nos estados de Minas Gerais (48,8\%), Pará (36,9\%), Goiás (6\%), Mato Grosso (4,6\%) e Bahia (3,7\%), que juntos somam mais de 90\% das reservas (MME, 2009). No ano de 2009 o cobre representou 4,43\% de toda a produção comercializada (metais e não metais) no Brasil; e o ouro 6,79\% no mesmo ano (DNPM, 2010).

Destarte, pode-se afirmar que o município de Alto Horizonte exerce papel importante na extração desses dois minérios no estado de Goiás e no Brasil, sendo importante exportador dessas substâncias. Os dados do DNPM (2015) denotam isso, destacando que, no ano de 2014, o município participou com 97,94\% do VPC de cobre do estado de Goiás e com $20,21 \%$ do VPC do ouro.

No que se refere à comercialização do cobre e do ouro extraídos nesse município, grande parte foi comercializada com os mercados internacionais. Os minérios foram exportados nesse ano para dois continentes distintos: Ásia e Europa. A Índia foi seu principal parceiro comercial, absorvendo $41 \%$ das exportações desse município. Em seguinte vem a Espanha (22,27\%), China (17,76\%), Coréia do Sul (14,49\%) e Alemanha absorvendo 4,40\% das exportações de Alto Horizonte (MCE, 2017).

\section{A MINERAÇÃO E A DINÂMICA ECONÔMICA DE ALTO HORIZONTE}

Desde a instalação do campo de extração mineral em Alto Horizonte, percebe-se a recorrência de notícias na mídia versando sobre o crescimento econômico do município. No período de 2004 a 2014 sua economia apresentou índices de crescimento muito acima da média estadual e nacional, registrando $3.562 \%$ de crescimento. Como mostra a Tabela 1, em 2004 seu PIB era de quase 13 milhões de reais, chegando a 471 milhões no ano de 2014. 
Tabela 1: Comparação do Crescimento do PIB de Alto Horizonte - Goiás, 2004-2014

\begin{tabular}{lccc}
\hline & \multicolumn{2}{c}{ PIB (R\$ Mil) } & Cercimento \\
\cline { 2 - 3 } & 2004 & 2014 & $(\%)$ \\
\hline Alto Horizonte & 12.875 & 471.462 & 3562 \\
Microrregião de Porangatu & 1.989 .409 & 5.033 .670 & 253 \\
Mesorregião do Norde Goiano & 2.389 .648 & 5.873 .569 & 246 \\
Estado de Goiás & 51.103 .815 & 165.015 .318 & 323 \\
\hline
\end{tabular}

Fonte: Sistema de Recuperação Automática - SIDRA - IBGE (2016). Elaborado pelos autores.

O setor industrial, mais especificamente a indústria da mineração instalada no município, é o principal indutor do crescimento econômico. Como evidência a Tabela 2, esse setor foi o que mais cresceu no período de 2004 a 2014, passando a representar $67 \%$ de seu PIB nesse último ano. Em decorrência, Alto Horizonte deixou de ser um município rural para tornar-se um município com economia baseada na indústria. Em 2004 a agropecuária representava o maior percentual na geração de riquezas, sofrendo queda vertiginosa, assim como setor da administração pública, na participação do PIB no ano de 2014.

Tabela 2: Evolução do Valor Adicionado Bruto do PIB por setor econômico em Alto Horizonte - Goiás, 2004-2014

\begin{tabular}{lcc}
\hline \multirow{2}{*}{ Setor Econômico } & \multicolumn{2}{c}{ VAB (\%) } \\
\cline { 2 - 3 } & 2004 & 2014 \\
\hline Administração Pública & 34 & 9 \\
Agropecuária & 42 & 2 \\
Indústria & 3 & 67 \\
Serviços & 21 & 22 \\
\hline
\end{tabular}

Fonte: Sistema de Recuperação Automática - SIDRA - IBGE (2016). Elaborado pelos autores.

Destarte, a realidade desse município é distinta da maioria dos municípios da região norte de Goiás, que têm suas economias baseadas na agropecuária, no setor de serviços e, em alguns, na administração pública. Todavia, ressalta-se que a riqueza produzida em Alto Horizonte é concentrada, sendo responsável por esse crescimento a empresa Maracá Indústria e Comércio S.A, o que permite inferir que, apesar do elevado PIB, em comparação com sua população e com os municípios do norte de Goiás, Alto Horizonte não possui uma economia dinâmica, sendo dependente da indústria de extração mineral.

Seu PIB per capita também é um dos mais elevados de Goiás, alcançando no ano de 2014 R\$ 88.837,82. Em decorrência da mineração, o município possui uma das maiores 
rendas médias de Goiás. No ano de 2000, Alto Horizonte ocupava a $231^{\circ}$ posição entre os municípios goianos com uma renda média de $\mathrm{R} \$ 228,27$. Com a chegada da mineração industrial o município passou a ocupar a $4^{\circ}$ posição entre os municípios goianos com as maiores rendas médias, atingindo o valor de $\mathrm{R} \$ 2.685,49$ (IMB, 2016).

Essa realidade se dá em decorrência dos altos cargos de gerência e pesquisa que a mineradora oferece. Entretanto, esses cargos são ocupados por profissionais que não são do município, vindos de outras regiões de Goiás e do Brasil, restando aos moradores locais e da região os empregos de menor conhecimento científico e remuneração, a maioria ligados às atividades desenvolvidas no interior das minas.

O setor da mineração ainda foi responsável por movimentar outros setores da economia do município, principalmente o setor terciário, serviços e comércio. Todavia, analisando a evolução da participação desse setor no PIB percebe-se que permaneceu praticamente estacionado. $O$ índice se dá em decorrência do grande crescimento da participação da indústria, mantendo, em números totais, o setor de serviços com a mesma participação. Foi realizado um trabalho de campo na cidade de Alto Horizonte, no qual foram aplicados questionários aos comerciantes, além de realizar entrevista com representante da prefeitura.

O questionário foi aplicado a um total de 20 comerciantes, dos quais 17 responderam. A ferramenta visa entender melhor as mudanças provocadas na economia do município de Alto Horizonte após a implantação da indústria mineral. As empresas comerciais da cidade encontram-se de forma concentrada ao logo da Avenida Getúlio Vargas e entorno da Praça Pedro Dias, no centro da cidade.

Dos 17 comerciantes que responderam o questionário, 52\% dizem ter se instalado no município após a chegada da atividade de extração mineral, ou seja, mais da metade dos comércios entrevistados foram criados após a chegada da mineração. Quanto ao faturamento, $94 \%$ dos comerciantes ${ }^{4}$ afirmam que houve incremento no faturamento de suas empresas.

Dentre as justificativas dos comerciantes para o aumento do faturamento, estão: o aumento da demanda de serviços na cidade; crescimento do fluxo de pessoas; da renda salarial dos moradores; maior número de empresas que se instalam no município, grande parte para prestar serviços à mineradora; aumento no número de empregos, devido à instalação da mineradora; e pelo crescimento da população de Alto Horizonte, que recebe migrantes de outras cidades e estados.

\footnotetext{
${ }^{4}$ Incluem-se nesse dado os comerciantes que se instalaram após o aparecimento da mineração, sendo que esses também afirmam aumento nas suas vendas desde sua instalação no município.
} 
Por outro lado, apenas $6 \%$ dos comerciantes indicaram que houve pouco aumento no faturamento de seu comércio. Dentre a justificativa para a resposta, está a desvalorização do comércio local, tendo em vista que muitos dos moradores da cidade procuram localidades vizinhas para realizarem suas compras, além de muitos trabalhadores da mineradora não residirem em Alto Horizonte.

As informações obtidas com os questionários ainda revelam que dentre as empresas que já haviam se instalado no município antes do início da exploração mineral, houve um aumento médio de $75 \%$ em seus funcionários. Outro fator importante a ser destacado com a pesquisa é que $100 \%$ das empresas entrevistadas, dentre os que já estavam instalados no município antes da abertura da mineração, dizem não ter mudado de ramo por conta da atividade mineral, todos continuaram no mesmo seguimento em que se encontravam desde 2004.

Esse incremento na atividade comercial é corroborado pelos dados da Prefeitura de Alto Horizonte. Por meio de dados fornecidos, percebe-se que o município recebeu um maior número de empresas a partir do ano de 2006. Esse aspecto pode ser observado na Tabela 3.

Tabela 3 - Número de empresas criadas no município de Alto Horizonte no período de 20002014

\begin{tabular}{ccc}
\hline Período & $\begin{array}{c}\mathrm{N}^{\circ} \text { de } \\
\text { empresas } \\
\text { criadas }\end{array}$ & $\begin{array}{c}\text { Permanecem com } \\
\text { CNPJ ativo (\%) }\end{array}$ \\
\hline $2000-2005$ & 169 & 20 a 30 \% \\
$2006-2014$ & 749 & $72 \%$ \\
\hline
\end{tabular}

Fonte: Prefeitura de Alto Horizonte (2014).

Por meio da análise da referida Tabela, é possível perceber que no período de 2006 a 2014, houve um aumento de $343 \%$ no número de empresas criadas no município, em relação ao período anterior de 2000 a 2005. De 2006 a 2014 foram criadas 749 novas empresas. Dessas, 539 ainda tem seus registros e pessoa jurídica ativa (72\%), das quais 30 a $35 \%$ não estão faturando, por motivos de falência, não procedendo à baixa do estabelecimento na prefeitura, por motivos de abandono e outros, ao passo que $28 \%$ das empresas criadas nesse período fecharam as portas (ALTO HORIZONTE, 2014).

A rotatividade dos $28 \%$ pode ser explicada, como aponta a Secretaria de Finanças de Alto Horizonte, pelo fato de que algumas empresas são registradas apenas para prestarem serviços à Mineração Maracá Indústria e Comércio S.A e à Prefeitura da cidade. Findado o 
contrato de prestação de serviço, as empresas dão baixa em seu registro de pessoa jurídica. Por outro lado, observa-se que a taxa de empresas criadas que fecharam as portas recuou no período de 2006 a 2014 em relação ao período anterior de 2000 a 2005.

Todavia, esse dado ainda permanece elevado, tendo em vista que em média um terço das empresas criadas no município não permanecem ativas. A especialização produtiva e os interesses por trás das densidades técnicas instaladas no município com a chegada da mineração podem explicar as causas dessa dinâmica econômica.

Como nos aponta Castillo (2007), as especializações regionais, como a que ocorre no município de Alto Horizonte, no caso da produção de commodities, vêm acompanhadas pela vulnerabilidade territorial, pois os preços da comercialização de seus produtos passam a ser regulados por mercados imprevisíveis e incontroláveis. Desse modo, qualquer flutuação no mercado internacional irá afetar diretamente outros segmentos econômicos locais.

Arroyo (2001) ainda acrescenta que essas vulnerabilidades aumentam à medida que os grandes grupos industriais alteram suas estratégias de investimentos, ao "financeirizar" suas reservas de capital, tornando as regiões ainda mais sujeitas às flutuações e instabilidades do mercado internacional.

Dessa forma, grande parte das regiões especializadas na extração mineral se tornam dependentes dos campos de extração, como é o que ocorre em Alto Horizonte. Segundo Milton Santos (1996):

Os sistemas técnicos atuais são dotados de uma enorme capacidade de invasão, mas essa invasão é limitada exatamente porque esses objetos estão a serviço de atores e forças que somente se aplicam se têm a garantia do retorno aos seus investimentos, seja investimento político, econômico ou cultural. (SANTOS, 1996, p. 114)

Como nos aponta o autor, essa densidade técnica é implantada com o objetivo de assegurar os interesses de atores hegemônicos que, nesse caso, não são pertencentes à região. Portanto, não são instaladas de acordo com o interesse dos atores locais, sendo, muitas vezes, estranhas a esses. Esses sistemas de engenharia (sistemas técnicos) estarão distribuídos no território de forma adequada a atingir os resultados que são esperados pelos atores hegemônicos.

Portanto, o Estado, principalmente na esfera municipal, acaba por privilegiar as commodities minerais extraídas em seus territórios em detrimento de outras atividades econômicas para o mercado local e regional. Como resultado, os municípios, bem como as regiões, se veem dependentes economicamente dos campos de extração. 
Dessa forma, a densidade técnica presente no município de Alto Horizonte é criada e utilizada/reutilizada em favor exclusivo do setor produtivo dominante, no caso, o setor mineral, afetando o bom desempenho e independência de outros setores econômicos. $\mathrm{O}$ capital hegemônico passa a possuir privilégios sobre o uso dos bens públicos, pressionam pela ampliação das infraestruturas e vinculam a economia local e regional a seus sistemas. As densidades técnicas, nesse caso, estão direcionadas ao uso por alguns agentes.

Esse processo pode explicar a grande rotatividade de empresas no município, bem como o motivo de que $100 \%$ dos comércios entrevistados não mudaram de ramo desde a implantação da mineração. A indústria mineral instalada em Alto Horizonte não realiza contratos com as empresas locais. Foi possível perceber que os serviços terceirizados pela mineradora são firmados com empresas que vêm de outros municípios. Muitas dessas empresas são criadas/registradas na prefeitura apenas para dar segmento ao contrato firmado.

Portanto, observa-se o crescimento econômico observado está relacionado aos interesses de agentes externos ao município, fazendo que os indicares econômicos estejam atrelados a empresas que são externas e pressionam pela exploração dos recursos naturais de acordo com interesses exógenos a Alto Horizonte.

Apesar do crescimento econômico, em visita de campo constatou-se que o município ainda é deficitário quanto a alguns serviços, não existindo alguns segmentos de serviços e de comércios (clínicas, concessionárias, serviços bancários e administrativos, corretoras imobiliárias, dentre outros) levando a população a recorrer a outras localidades.

Assim, pode-se perceber que a instalação da indústria mineral no município de Alto Horizonte foi substancialmente importante para o crescimento de sua economia.

No entanto, a mineração não proporciona a dinamização do comércio local, tendo em vista que muitos trabalhadores moram em cidades vizinhas, dirigindo-se a Alto Horizonte apenas para trabalhar na mina. Some-se a esse fato o privilégio dado, em detrimento dos segmentos locais, pelo poder público municipal ao agente hegemônico - a grande indústria da extração mineral - que possui intensas relações com o mercado nacional e internacional, contribuindo para vulnerabilidade territorial econômica no município.

Do mesmo modo os elevados números que indicam a renda média da população empregada em Alto Horizonte, apontados anteriormente, por si só não indicam a realidade econômica da população local. São necessários outros fatores para poder apontar a existência de um desenvolvimento local, dentre os quais se podem destacar: a distribuição da riqueza com poucas distorções com relação à remuneração da população; baixos níveis de desemprego; diminuição das acentuadas desigualdades sociais; elevação das condições de 
saúde, higiene, moradia e outras variáveis sociais que são específicas de determinadas culturas, como nos aponta Becker (2008).

\section{A MINERAÇÃO E A DINÂMICA TERRITORIAL DE ALTO HORIZONTE}

Com a implantação da planta de extração mineral no município de Alto Horizonte e com a consequente mudança em sua dinâmica econômica, o município passa a apresentar uma nova dinâmica territorial. A principal mudança em sua dinâmica territorial está relacionada ao processo de expansão urbana no município, que está diretamente relacionada à presença da indústria de extração mineral. Para Lefebvre (2008) a industrialização é indutora do processo de urbanização.

Para o autor, a acumulação de riquezas passa a se concentrar nas cidades por meio do estabelecimento da técnica e do sistema monetário, ambos induzidos pela industrialização. Milton Santos (1994) também acrescenta a modernização como representação do processo de expansão do sistema capitalista, tanto nas áreas rurais quanto urbanas, como elemento indutor do processo de urbanização:

Temos uma modernização e ampliação dos transportes e das comunicações como uma expansão capitalista no campo e nas demais atividades; um movimento de migrações muito forte; uma nova divisão do trabalho social e territorial, que se sobrepões à divisão do trabalho social e territorial anterior, etc. Tudo isto como resultado, uma aceleração do processo de urbanização. (SANTOS, 1994, p. 90)

Segundo Arrais (2013), dois debates são recorrentes nos estudos sobre urbanização. O primeiro atrelado ao processo de industrialização, indutor da migração do campo, e o segundo que trata do significado do termo urbanização, pois o autor afirma que a análise desse processo não deve se restringir apenas a dados quantitativos.

Assim, além de uma análise estatística, as discussões sobre urbanização evidenciam as intensas transformações do mundo contemporâneo, requerendo uma fuga à oposição entre rural e urbano (ARRAIS, 2013). A respeito dessa sacramentada oposição, Castells (1983), mostra que:

\footnotetext{
Mas então não existiria mais separação entre "cidade" e "campo"? É a "urbanização" generalizada? Na realidade, esta problemática não tem sentido (outro que ideológico) como tal, colocada nos termos em que se coloca mais frequentemente. Porque ela pressupõe já a distinção e mesmo a contradição entre rural e urbano, oposição e contradição que tem sentido no capitalismo. Os espaços de produções e de consumo na fase monopolista do capitalismo estão fortemente interpenetrados, imbricados, segundo a organização e o desenvolvimento desigual dos meios de produção e dos meios de consumo, não se fixando enquanto espaços
} 
definidos senão num dos polos da divisão social do trabalho. (CASTELLS, 1983, p. 476)

Dessa forma, na atualidade, com a expansão do meio técnico-científicoinformacional $^{5}$ no espaço, termo explorado por Milton Santos (2006), torna-se complicado delimitar o que é urbano e o que é rural, sendo que em determinados momentos esses espaços se confundem. Em Alto Horizonte com a implantação de redes de circulação e comunicação no território e com intensificação das trocas regionais e internacionais, as relações entre a cidade e o campo se intensificam e tornam-se mais complexas.

Não se pode dizer que o campo, nesse caso mais precisamente o local de extração mineral, é extensão do urbano, pois, segundo Arrais (2013), a intensa integração entre ambos torna difícil a delimitação das fronteiras que os separam. Essa é uma das mudanças espaciais provocada pelo capital minerador no município de Alto Horizonte: a intensa interação entre campo e cidade.

Dessa forma, o campo e a cidade se misturam devido à expansão dos meios de fluidez do capital - vias de transporte; redes de comunicação e as intensas trocas comerciais e informacionais que conectam o território de Alto Horizonte tanto em nível estadual, nacional e internacional.

Nessa esteira, as cidades ${ }^{6}$ são vistas, genericamente, como o espaço de maior ocupação de trabalhadores, que mais oferece empregos. No entanto, em cidades com extração mineral, essa realidade é invertida. A cidade não é mais a principal empregadora, revertendo esse papel para campo, no caso o local específico de extração mineral, geralmente situado fora dos perímetros urbanos.

Assim, os trabalhadores viajam da cidade para a mina de extração. Há uma "migração" do local de trabalho, ficando para a cidade os serviços auxiliares da economia hegemônica, no caso a extração mineral, como: serviço de transportes, de saúde, de alimentação, as repartições públicas e o comércio. É uma intensificação da divisão social do trabalho.

\footnotetext{
5 [...] técnico-científico-informaciona96 é o meio geográfico do período atual, onde os objetos mais proeminentes são elaborados a partir dos mandamentos da ciência e se servem de uma técnica informacional da qual thes vem o alto coeficiente de intencionalidade com que servem às diversas modalidades e às diversas etapas da produção. (SANTOS, 2006, p. 157)

${ }^{6}$ Utiliza-se desta parte da discussão do texto, ao analisar a oferta de emprego em municípios com indústrias de extração mineral, o termo "cidade" em seu sentido morfológico, que implica considerar o perímetro urbano as áreas que contém como infraestrutura os serviços classificados como urbanos (ruas asfaltadas; telefonia, coleta de lixo, saneamento, redes de água e etc.).
} 
Como efeito $^{7}$ da mineração industrial, o município também observou crescimento populacional. No censo de 2000, Alto Horizonte possuía uma população de 2.564 habitantes, chegando a 4.505 na contagem de 2010 (IBGE, 2016). Levando em conta esse período, a população cresceu 75\%. Para 2014, estima-se que o município tenha 5.307 habitantes (IBGE, 2016). Esse crescimento populacional anda na contramão da realidade da mesorregião norte de Goiás (Figura, 2).

Figura 2: Evolução populacional dos municípios da Mesorregião Norte de Goiás, 2000-2010.

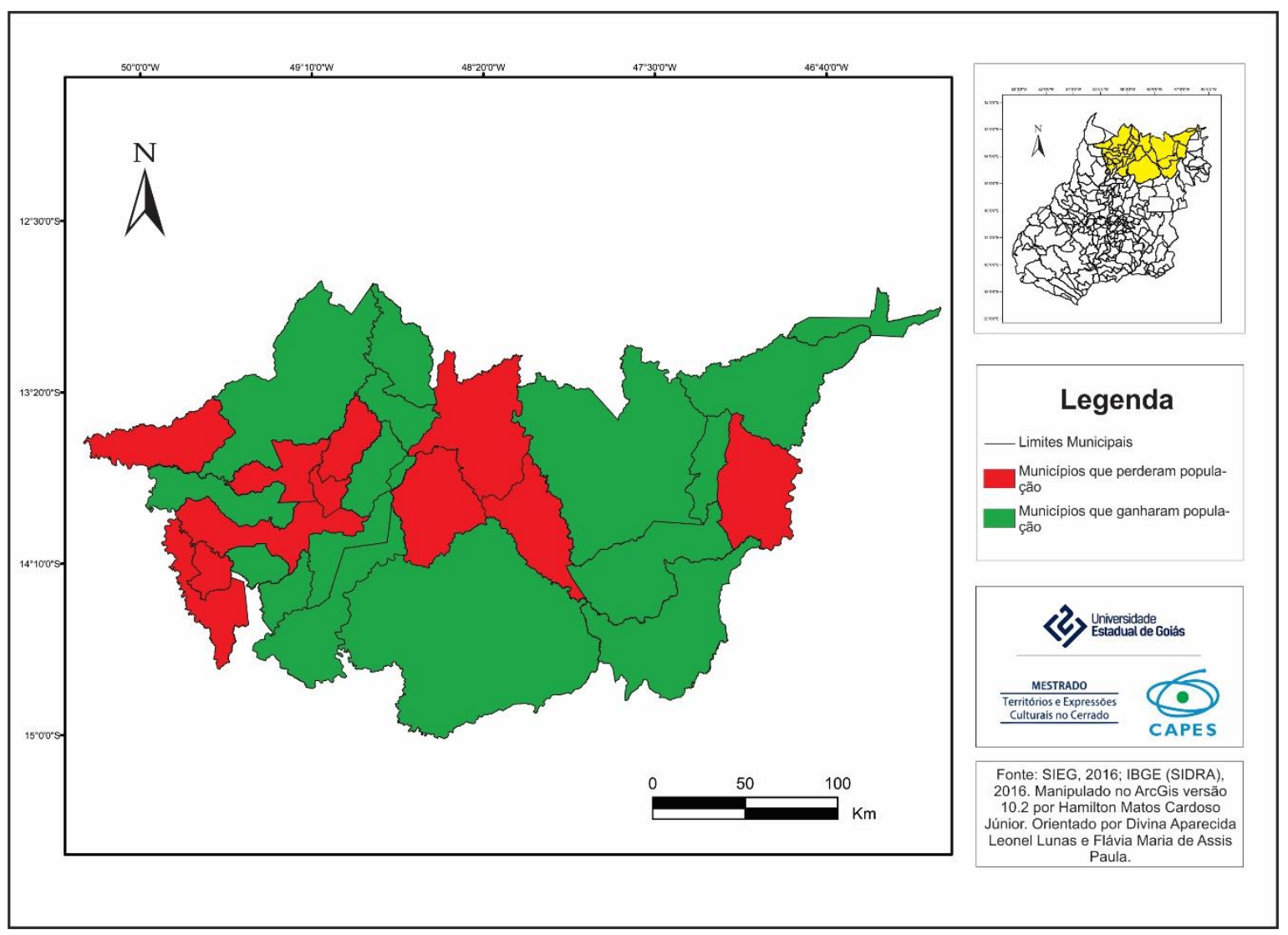

Dos 27 municípios que compõem essa região 11 perderam população no período de 2000 a 2010. Perderam mais, sendo os casos mais preocupantes, os municípios de Campos Verdes (-37,69\%); Santa Tereza de Goiás (-14,94\%) e Santa Terezinha de Goiás $(-14,25)$.

Por outro lado, Alto Horizonte lidera os 16 municípios que ganharam população nesse período. Destacam-se na atração de população: Alto Horizonte (75,70\%); São João

\footnotetext{
${ }^{7}$ Todavia, cabe destacar que o elevado nível de investimentos em capital fixo na mina, resulta em um menor número de pessoas empregadas como se tinha nos garimpos, pois, como mostrou Singer (1987), a automatização da produção passa pela substituição do homem pela máquina. Processo que é benéfico para a acumulação capitalista, uma vez que há potencialização da produção e diminuição de gastos com mão de obra.
} 
D’Aliança $(52,27 \%)$ e Bonópolis $(34,83 \%)$. Na Figura 2 observam-se os municípios que ganharam e perderam população na mesorregião norte de Goiás no período analisado.

Dessa forma, a atividade mineral em Alto Horizonte propiciou crescimento populacional do município, tendo em vista que sua população foi a que mais cresceu na região dentro do período analisado. O fluxo populacional em direção ao município acabou provocando mudanças e reordenamento na área urbana da cidade.

Segundo o representante da prefeitura - em entrevista concedida para esta pesquisa com relação às mudanças urbanas ocorridas no município devido à implantação do campo de extração, a cidade recebeu "[...] melhorias em ruas, avenidas, melhor mobilidade, escolas, centro de saúde, novos bairros com infraestrutura implantada, como água, luz e saneamento" (ENTREVISTADO A).

Ao observar imagens de satélite do núcleo urbano de Alto Horizonte, percebe-se o processo de expansão urbana, ocorrida, principalmente após o ano de 2004. Houve expansão com abertura de novos loteamentos, que foram rapidamente ocupados pelo grande contingente populacional que havia chegado ao município. Vale ressaltar que todos os novos loteamentos foram de iniciativa da prefeitura. As Figuras 3 e 4 nos mostram a expansão urbana de Alto Horizonte.

Figura 3: Imagem de satélite da área urbana de Alto Horizonte - 2004.

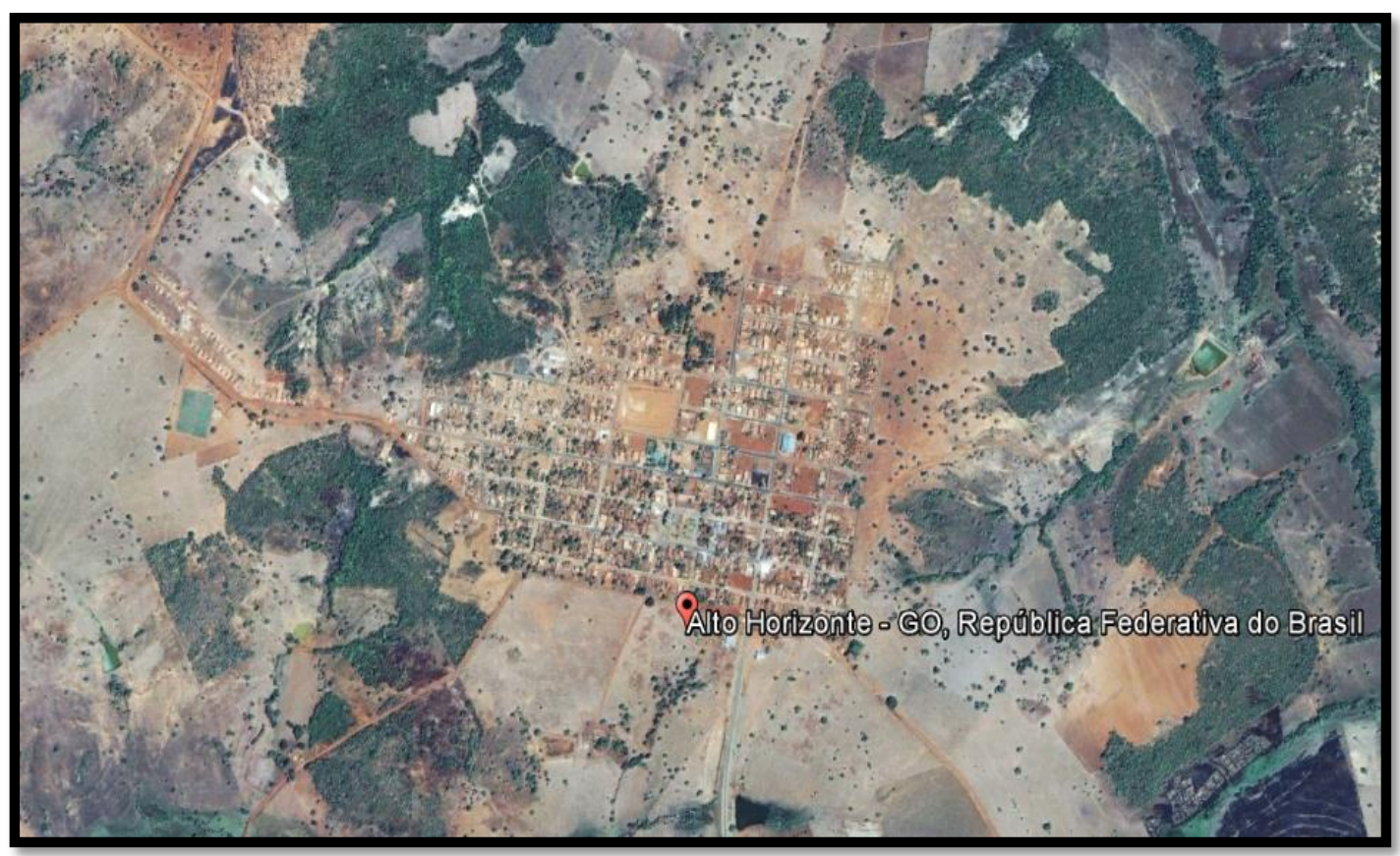

Fonte: Google Earth, 2003. Disponível em:

$<$ https://maps.google.com.br/maps?output=classic\&dg=brw $>$. 
Figura 4: Imagem de satélite da área urbana de Alto Horizonte - 2014.

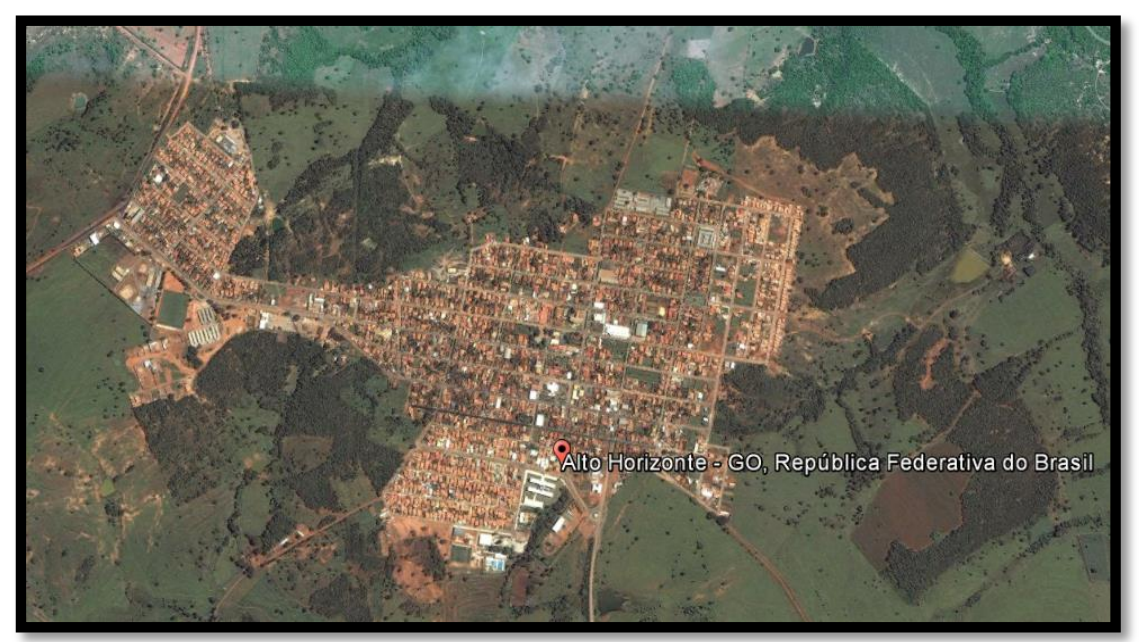

Fonte: Google Earth, 2014. Disponível em:

$<$ https://maps.google.com.br/maps?output=classic\&dg=brw $>$.

No período analisado (2004 a 2014), conforme dados da prefeitura local, foram criados os bairros: Setor Residencial Sul I e II etapa e Setor Residencial José Basílio. No presente momento (2014) está em fase de implantação o Setor Agroindustrial de Alto Horizonte, que - segundo a prefeitura - é um dos investimentos públicos destinado a dar independência à economia do município. Além disso, houve grande expansão do Bairro Nossa Senhora Aparecida, que quadruplicou de tamanho, e do Bairro Bela Vista.

Além da abertura de novos bairros, também houve adensamento da área central da cidade, que recebeu novas construções, ocupando espaços/lotes que ainda estavam vagos. Pela análise das Figuras 3 e 4, percebe-se que novas construções foram realizadas no traçado original da cidade, o que contribuiu para maior adensamento predial urbano.

Houve ainda, conforme o representante da prefeitura entrevistado, a regularização fundiária dos lotes e residências já existentes no centro da cidade, tendo em vista que muitas construções ainda não possuíam escritura.

Dessa forma, a chegada/inserção do setor mineral no município foi preponderante para a expansão urbana da cidade de Alto Horizonte, à medida que, pela necessidade de abrigar tal aumento no contingente populacional, viabilizou a abertura de novos setores e o adensamento dos já existentes.

Outra mudança perceptível no espaço urbano de Alto Horizonte e que foi ocasionada pela presença da mineração industrial e pelo consequente crescimento da economia do município, é a valorização fundiária e o aumento dos preços locacionais dos imóveis. Essa 
mudança pode ser explicada, em parte, pela intervenção estatal ao regularizar lotes e residências no centro cidade, pelo aumento na procura por residências em virtude da chegada de novos trabalhadores e morados à cidade e pela especulação imobiliária devido ao expressivo do crescimento da economia municipal e da oferta de empregos.

Por outro lado, também houve uma reconfiguração/reestruturação das vias de circulação urbana. Anteriormente à expansão urbana, todas as vias da cidade eram simples, estreitas e algumas ainda encontravam-se sem asfalto. Ao andar pela cidade é facilmente perceptível a diferença dos bairros novos com o centro. Os novos setores já possuem avenidas de duas pistas e ruas mais largas, proporcionando maior fluidez. As ruas sem asfalto no traçado original da cidade também foram asfaltadas.

Os prédios públicos também sofreram reconfigurações. Foram construídos novos prédios para o Centro Administrativo (prefeitura), Câmara Municipal e para as secretarias municipais. Ainda foram abertos espaços para o Parque de Exposição Agropecuária de Alto Horizonte e a cobertura de quadras de esporte.

Após a instalação da mineração, construíram-se também pequenos conjuntos habitacionais em Alto Horizonte, destinados a abrigar trabalhadores de cargos mais elevados da mineradora. Também se tem observado a presença de empresas concentradas na saída para o campo de extração, ao longo da Avenida Caraíba e Rio Preto. Empresas, essas, que atuam como prestadoras de serviço de transporte e de maquinário para a mineradora.

A nova dinâmica territorial de Alto Horizonte também altera a intensidade de suas interações espaciais. A mineração industrial do município e sua densidade técnica insere Alto Horizonte no circuito espacial global da exploração e comercialização de minérios. Nesse sentido, as interações do município intensificam na perspectiva multiescalar.

Há intensificação das relações com a região, tendo em vista que o município passa a empregar trabalhadores dos municípios vizinhos, fortalecendo seu papel na divisão regional do trabalho e na rede de interações intermunicipais recebendo migrações pendulares. Do mesmo modo, Alto Horizonte também fortalece suas relações com outros municípios ao garantir/instalar suas redes de circulação e escoação da produção para o mercado consumidor ${ }^{8}$.

Por outro lado, também há uma intensificação de suas relações espaciais no plano nacional. Analisando o circuito espacial da empresa Yamana Gold no Brasil observa-se que

\footnotetext{
${ }^{8} \mathrm{O}$ transporte do cobre para o mercado consumidor (internacional) ocorre por meio do Porto Seco do Centro Oeste instalado em Anápolis por via férrea. Já o ouro, em virtude de seu agregado valor, é exportado por via área por meio de helicópteros e pequenos aviões que fazem uso do pequeno aeroporto municipal criado com essa finalidade.
} 
há uma verticalização do território, elegendo regiões do mandar e do fazer (SANTOS, 2006). Em Alto Horizonte está instalada a base operacional, a mina de extração. Todavia, o centro de tomada de decisões dessa empresa localiza-se nas cidades de São Paulo (escritórios operacionais) e Toronto - Canadá (sede da empresa). Portanto, Alto Horizonte, nessa perspectiva, assume papel na divisão internacional do trabalho, definindo seu papel na verticalização do território.

Por fim, o município ainda estreita suas relações com o plano internacional à medida que integra o circuito espacial da produção e os círculos de cooperação no espaço do setor mineral industrial. Nesse sentido, a nova dinâmica territorial de Alto Horizonte resulta em mudanças espaciais locais (em seu território), bem como nas suas interações que agora se estabelecem no plano regional, nacional e internacional.

\section{CONSIDERAÇÕES FINAIS}

Alto Horizonte tem se firmado como um dos principais polos minerais do estado e do Brasil por possuir importância na extração do cobre e do ouro. $\mathrm{O}$ emprego de técnicas viabilizadas pelos altos investimentos realizados no campo de extração do município - Mina da Chapada - contribui para a maximização da extração desses minérios.

A indústria da mineração em Alto Horizonte contribui para alicerçar o setor mineral em Goiás com base em conhecimentos científicos, técnicos e mercadológicos. A estrutura criada no município mostra-se, nessa primeira década, produtiva, sólida e lucrativa. O setor tem desempenhado cada vez mais papel de importância na economia goiana.

Esse setor da economia, que se firmada hegemônico no município, tem imprimido uma nova dinâmica territorial e econômica em Alto Horizonte. Com relação a sua economia, o município experimenta o crescimento de seu PIB, aumento no número de postos de trabalho e de empresas criadas.

Todavia, observa-se que a mineração tem provocado vulnerabilidade territorial de ordem econômica em Alto Horizonte, tendo em vista que esse crescimento é representado apenas pela indústria da mineração (setor industrial), comandado por uma única empresa transnacional, atrelada às flutuações do mercado internacional, comprovando que o crescimento econômico é concentrado e desigual.

Há pouco dinamismo econômico, o setor agropecuário diminuiu sua participação no PIB e o setor de serviços, por outro lado, apresentou-se estagnado no período analisado. Essa realidade econômica apresenta-se preocupante, tendo em vista que o município torna-se 
totalmente dependente da indústria da mineração, sendo essa uma atividade de exploração não infinita.

Por outro lado, a indústria da mineração também imprime uma nova dinâmica territorial ao município, notadamente: a expansão urbana; valorização imobiliária das construções urbanas e de fazendas; acelerado crescimento populacional; reordenamento urbano; ampliação das redes de comunicação e transporte em seu território e ampliação das relações desse município com a escola regional, nacional e internacional.

Por fim, Alto Horizonte foge às características dos demais municípios que participam da mesorregião norte por sua pujança econômica. O município tende a fortalecer a presença do capital internacional no setor mineral em Goiás, capital que é elemento propulsor da nova dinâmica territorial e econômica nesse município.

\section{REFERÊNCIAS BIBLIOGRÁFICAS}

ARRAIS, Tadeu Alencar. A produção do território goiano: economia, urbanização, metropolização. Goiânia: Editora da UFG, 2013.

ARROYO, Maria Mônica. Território Nacional e Mercado Externo: uma leitura do Brasil na virada do século XX. 2011. 250 f. Tese (Doutorado em Geografia Humana) Departamento de Geografia, Faculdade de Filosofia, Letras e Ciências Humanas, Universidade de São Paulo (USP), São Paulo - SP, 2001.

BARBOSA, Altair Sales; SCHMITZ, Pedro Ignácio; TEIXEIRA NETO, Antônio; GOMES, Horieste. O piar da Juriti Pequena: narrativa ecológica da ocupação humana do cerrado. Goiânia: Editoria da PUC Goiás, 2014.

BECKER, Dinizar Fermiano. A contradição em processo: o local e o global na dinâmica do desenvolvimento regional. In: BECKER, Dinizar Fer,omamp; WITTMANN, Milton Luiz. Desenvolvimento regional: abordagens interdisciplinares. 2. ed. Santa Cruz do Sul: EDUNISC, 2008, p. 67- 115.

CASTELLS, Manuel. A questão urbana. Rio de Janeiro: Editora Paz e Terra, 1983.

CASTILlO, Ricardo. Agronegócio e Logística em Áreas de Cerrado: expressão da agricultura científica globalizada. In: Revista da ANPEGE. v. 3, 2007, p. 33-43.

CASTRO, Mário César Gomes. Mineração e Economia de Goiás. In: CASTRO, Joana D’arc Bardella (org.) et. al. Economia Goiana: Cadeias Produtivas, Reestruturação, Mineração, Agricultura e Industrialização. Anápolis: Editora da UEG, 2006, p. 87-111.

COSTA, Vinicius. Produção de Concentrado de cobre e ouro segue até 2029 em Alto Horizonte - GO. In: Revista Minérios e Minerales, São Paulo, 2014. Disponível em: < http://www.revistaminerios.com.br/Publicacoes/5093/Producao_de_concentrado_de_cobre_ e_ouro_segue_ate_2029_em_Alto_Horizonte_GO.aspx>. Acessado em: setembro de 2014 . 
DNPM. Departamento Nacional da Produção Mineral (DNPM). Anuário Mineral Brasileiro 2010 (ano base 2009). Brasília: DNPM, 2010.

DNPM. Departamento Nacional da Produção Mineral (DNPM); Superintendência Goiás/Distrito Federal. Desempenho do Setor Mineral de Goiás - 2015 (ano base 2014). Disponível em: < http://www.dnpm.gov.br/go/conteudo.asp?IDSecao=614>. Acessado em: julho de 2014.

ESTEVAM, Luís. O tempo da transformação: estrutura e dinâmica da formação econômica de Goiás. 2. Ed. Goiânia : Ed. UCG, 2004.

GOIÁS. Lei no 11.399, de 16 de janeiro de 1991. Criação do Município de Alto Horizonte. Disponível em: < http://www.gabinetecivil.goias.gov.br/leis_ordinarias/1991/lei_11399.htm>. Acessado em: setembro de 2014.

IBGE. Instituto Brasileiro de Geografia e Estatística - Sistema de Recuperação Automática (SIDRA). Rio de Janeiro: IBGE, 2016. Disponível em: <https://sidra.ibge.gov.br/home/ipca/brasil>. Acessado em: dezembro de 2016.

IBRAM. Instituto Brasileiro de Mineração (IBRAM). Yamana Recebe Prêmio "Empresa do ano do setor mineral", 2012. Disponível em: < http://www.ibram.org.br/150/15001002.asp?ttCD_CHAVE=228495>. Acessado em: setembro de 2014.

IMB. Instituto Mauro Borges de Estatísticas e Estudos Socioeconômicos (IMB). Estatísticas Municipais - Rendimento Médio. Goiânia: SEPLAN-GO, 2015. Disponível em: <http://www.imb.go.gov.br/>. Acessado em: setembro de 2015.

MCE. Ministério do Comércio Exterior. Balança comercial brasileira - municípios. Disponível em: <http://www.mdic.gov.br/comercio-exterior/estatisticas-de-comercioexterior/balanca-comercial-brasileira-municipios>. Acessado em: outubro de 2017.

MME. Ministério de Minas e Energia - Secretaria de Geologia, Mineração e Transformação Minera (SGM). Relatório Técnico 23: Perfil da Mineração de Cobre. Brasília: J. Mendo Consultoria, 2009.

SANTOS, Milton. A natureza do espaço - técnica e tempo. Razão e Emoção. São Paulo: Hucitec, 2006.

SANTOS, Milton. Técnica, espaço, tempo: globalização e meio técnico-científico informacional. São Paulo: Hucitec, 1996.

SANTOS, Milton. Urbanização Brasileira. 2º ed. São Paulo: HUCITEC, 1994.

SCHMALTZ, Walter Hugo. Evolução do setor mineral de Goiás. Goiânia: MME/DNPM, 1983.

SINGER, Paul. O Capitalismo: sua evolução, sua lógica e sua dinâmica. $6^{\circ}$ ed. São Paulo: Editora Moderna, 1987. 
SEGPLAN. Secretaria do Planejamento e Desenvolvimento (SEGPLAN); Superintendência de Estatística, Pesquisa e Informação. Goiás em dados 2014. Goiânia: SEPLAN-GO, 2015.

VIEIRA, Edson Trajano; SANTOS, Moacir José dos. Desenvolvimento Regional - Uma revisão histórica e teórica. In: Revista Brasileira de Gestão e Desenvolvimento Regional. v. 8, n. 2, 2012, p. 344-369. 